Article

\title{
Cultural Intelligence of Expatriate Health Workers in an Inuit Context: An Exploration of Managerial Competency Profiles
}

\author{
Geneviève Morin (D) and David Talbot*(D) \\ École Nationale d'Administration Publique (ENAP), 555 Boulevard Charest Est Québec, Québec, QC G1K 9E5, \\ Canada; genevieve.morin@enap.ca \\ * Correspondence: david.talbot@enap.ca
}

check for

updates

Citation: Morin, G.; Talbot, D. Cultural Intelligence of Expatriate Health Workers in an Inuit Context: An Exploration of Managerial Competency Profiles. Businesses 2021, 1, 1-17. https://doi.org/10.3390/ businesses1010001

Received: 28 January 2021

Accepted: 23 February 2021

Published: 8 March 2021

Publisher's Note: MDPI stays neutral with regard to jurisdictional claims in published maps and institutional affiliations.

Copyright: (c) 2021 by the authors. Licensee MDPI, Basel, Switzerland. This article is an open access article distributed under the terms and conditions of the Creative Commons Attribution (CC BY) license (https:// creativecommons.org/licenses/by/ $4.0 /)$.

\begin{abstract}
Developing cultural diversity skills is a major ethical challenge for organizations operating within marginalized communities. This study defines cultural intelligence profiles us a two-step approach. In the first step, managers $(n=31)$ are invited to complete a Cultural Intelligence Quotient Assessment Test to identify and describe different managerial profiles. In the second step, semistructured interviews are conducted $(n=17)$ to better understand the characteristics of the managerial profiles developed in phase one. The findings indicate that there are three typical managerial profiles: (1) The opportunist, (2) the modern missionary, and (3) the seasoned sage. These managerial profiles highlight the emerging dynamics of the cultural intelligence model and provide a better understanding of the career trajectories of managers in the healthcare sector. The results also have important managerial implications, particularly concerning strategies for training managers working with marginalized populations.
\end{abstract}

Keywords: cultural intelligence; cultural sensitivity; intercultural management; Nunavik; Inuit; Indigenous people; cultural minorities; healthcare

\section{Introduction}

Since the 1990s, the ability to adapt to and work in a variety of cultural contexts has been recognized as important for the effective functioning of culturally diverse organizations [1-4]. In Nunavik (Québec, Canada), 90\% of the population is Inuit, but nearly $60 \%$ of the healthcare managers are non-Inuit peoples [5]. Healthcare is primarily provided by nurses, general practitioners, and social workers who reside in the villages, but are both non-Inuit and come from southern Québec [6]. Virtually all managers and professionals are trained at southern educational institutions, where the curricula focus on the health needs of the white settler population [6]. Before beginning work in the North, health workers and managers receive two days of training on Inuit culture and life in the Arctic [7]. This brief introduction is highly insufficient and leaves managers and other professionals unprepared to work in Inuit communities [7].

Moreover, Nunavik's Inuit report that the healthcare services offered by their local public healthcare providers fall far short of their needs and expectations [8,9]. The fact that most healthcare workers in Nunavik come from southern Québec means that the healthcare system is structured according to Western medicine's siloed approach. Ultimately, this approach is incompatible with the holistic view of healthcare that is generally characteristic of Inuit culture. Among other things, this tension contributes to the various healthcare disparities and the lack of equitable access observed in the Nunavik healthcare system [10,11]. Another complicating factor is the legacy of decades of systemic violations, violence, and cultural genocide enacted against the Inuit peoples by successive Canadian governments, institutions, and individuals [12-17]. Recognition and reparations for these are an essential part of addressing healthcare inequities.

There are many models of cultural competency aimed at understanding and respecting differences among marginalized groups e.g., [18-20]. Cultural competence is often defined 
as an individual's ability to develop effective interpersonal and professional relationships that outweigh cultural differences. This competence requires recognizing the importance of marginalized communities' social and cultural norms [21]. However, the different understandings of cultural competence are generally oriented toward an individualized, rather than organizational or systemic, analysis [22]. Several authors also stress the importance of adopting more global approaches to integrate the environments in which the managers evolve into cultural competency models e.g., [22,23].

The present study mobilizes the concept of cultural intelligence (CQ) [24]. Initially, the CQ model was limited to analyzing the personal characteristics of individuals, whereas the present study has the following two objectives. First, it builds managerial CQ profiles. These profiles are derived from datasets characterizing managers behaviors. Second, this study offers a better understanding of the dynamics of the CQ model in general by showing how its dimensions interact with the environments in which managers' CQ develops. The Nunavik environment provides an excellent opportunity to explore the dynamics of CQ. The mixing of Inuit and white populations, and the cultural and socio-political upheavals affecting the Inuit way of life, is conducive to the study of this concept.

The current study makes four principal contributions to the literature on CQ. First, it provides a better understanding of the dynamics of the CQ model and the interactions between its different components. The importance of conducting studies in this area was noted by several researchers e.g., $[25,26]$. This research also develops managerial profiles that enrich the literature on CQ [27]. Moreover, our CQ profiles provide a better understanding of the interactions between individual characteristics and the environment in which they operate. The results of this study highlight the fact that the CQ model has internal paradoxes. For instance, a high CQ score does not necessarily correlate to culturally responsible behavior. As a result, the CQ level alone does not provide sufficient information to predict which managers will be most competent in culturally-unfamiliar contexts. Ultimately, the present study has important managerial implications, particularly for the importance of providing customized hiring training, but also for developing human resource management policies that ensure the development of cultural skills on the job. This study responds to the invitation of Ott and Michailova [26] to study under-researched sectors of activity (e.g., healthcare) by mobilizing qualitative methods to better understand the dynamics of the CQ model.

The remainder of this article is divided into five sections. The first section introduces the CQ model. The second section describes the Inuit peoples' holistic approach to healthcare, followed by the third section, which explains the present study's methodology. The fourth section is dedicated to analyzing the results, and the last section presents the discussion and conclusions of the study.

\section{The CQ Model}

Since Earley and Ang [24] introduced the concept of CQ, researchers in organizational psychology and human resources management have paid it considerable attention e.g., [26,28,29]. CQ is defined as an individual's capacity to both gain an overarching understanding of the values, beliefs, and behaviors typical of a culture other than their own and to use this knowledge to achieve specific goals. In this model, developing a person's capacity to adapt to another culture is more important than the transmission of knowledge about cultural differences between individuals. Ang and Van Dyne's [28] CQ model is based on a four-dimensional structure pictured below, in Figure 1. This dynamic CQ model is based on the fact that an individual is continuously developing skills to adapt to their environment. The metacognitive, cognitive, motivational, and behavioral dimensions of CQ form a cycle that leads the individual to update their skills regularly. The metacognitive dimension refers to the mental processes that allow individuals to be aware of and then reflect on their thoughts and emotions during intercultural interactions. The cognitive dimension is the product of one's knowledge about the values and the political, social, cultural, economic, and legal systems of other cultures. The motivational dimension refers to 
individuals' personal motivations to adapt to cultural situations. Ultimately, motivational CQ refers to a person's intrinsic and extrinsic interests, desires, and needs that motivate action, reflection, and adaptation [28]. The behavioral dimension reflects the ability to use culturally-appropriate and -sensitive communication and behaviors when interacting with individuals from other cultures.

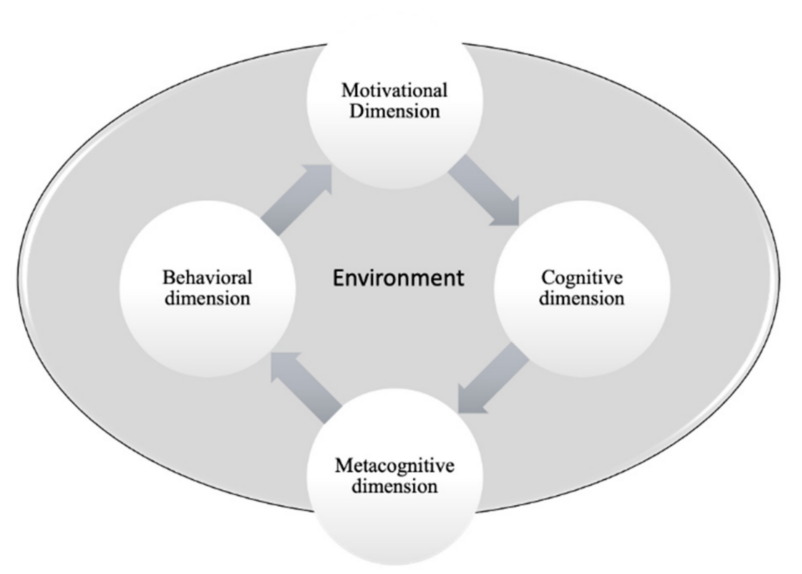

Figure 1. Four-dimensional cultural intelligence (CQ) model by Ang and Van Dyne.

\subsection{The CQ Model's Dynamism}

The CQ model is dynamic, as it is based on individuals' constant development of skills to adjust to their ever-changing environments. The different dimensions of CQ form a cycle that leads the individual to regularly update those skills $[29,30]$. The motivational dimension provides the drive and energy necessary to acquire new knowledge and develop the cognitive dimension. The new knowledge nourishes metacognitive reflection on behavior, thus contributing to that dimension. Reflection makes it possible to further adapt one's actions to the environment, thus contributing to the development of the behavioral dimension. Successful experiences with intercultural contact encourage individuals to repeat the experience, thus feeding the motivational dimension. In this model, individuals must have an overall repertoire of coping skills [31]. In this way, they can effectively adapt their leadership style to multicultural situations. They need these abilities because focusing on one without the others can lead to an increase in cultural ignorance rather than an improved CQ.

\subsection{Criticisms of the Model}

This model has significant limitations that can influence the interpretation of research results. First, the process of $C Q$ is reduced to an individual's intellectual capacity to develop or grow in a cultural context different from their home culture. Unfortunately, it is difficult to know how each individual develops and reinforces their CQ [26]. Thus, the model does not account for all forms of intelligence. Specifically, it does not consider perhaps one of the most important forms of intelligence for $C Q$, which is the ability to collect and adapt to unfamiliar and useful information. That is, the model does not take into consideration the individual's ability to develop contextual strategies and implement them. Second, it does not enable accurate and detailed identification and description of CQ profiles. For example, the model does not specify how dimensions interact with each other [26]. Moreover, there have been few theoretical developments on CQ since 2009 [25]. In their systematic review of the literature on $\mathrm{CQ}, \mathrm{Ott}$, and Michailova [26] show that most of the theoretical gaps have still not been addressed (e.g., how individuals develop CQ; interpretation of complex results; the interaction between dimensions). Our research provides empirical evidence addressing some of these unresolved theoretical gaps. Also, following Blasco and colleagues' [25] suggestion, rather than devote our energy to building new measurements and descriptions, we focus our efforts on empirical examples and methodologies that can help us test, modify, or refine the concept of CQ. 


\section{Inuit Health Conception}

Nunavik is located North of the 55th parallel, and it covers about $30 \%\left(500,164 \mathrm{~km}^{2}\right)$ of the Canadian province of Québec. Also, there are 14,000 people in 14 coastal villages. Notably, $90 \%$ of Nunavik's population is Inuit, and their living conditions are quite different from those found elsewhere in Québec and across most of Canada (e.g., overcrowded housing, difficult access to affordable food, no road connects the villages) (RRSSSN, 2015a, 2015b).

Indeed, the Nunavik health care profile reveals many discrepancies between the health status of Nunavimmiut and other Quebecers [32]. Due to their institutionalized nature, these inequities arise for Nunavummiut from early childhood and persist until death [33]. This public health crisis has been highlighted several times in recent years [10] in scientific e.g., [34], organizational [32,33], and governmental publications e.g., [35]. Years of research have shown that Inuit in Canada suffer a higher percentage of severe health problems than the rest of the population [10]. Inuit, like other Aboriginal peoples in Canada, experience disproportionately high suicide rates compared to non-Aboriginal populations [34]. Although Aboriginal communities and organizations have developed local and regional approaches to prevention, public health systems continue to face challenges, and national health data systems lack Aboriginal identifiers.

These elements remind us that the colonization of the Canadian North was first imagined and then forcefully achieved through various means, such as violence, residential schools, and genocide [36]. Moreover, this process has been deeply anchored in law, culture, and institutions. The institutional dynamic continually renews the power and power relations that have historically disadvantaged Canada's Indigenous peoples [37]. Ultimately, Nunavik's Inuit have had to make profound cultural changes, which are imposed and reinforced by the various levels of Canada's (starting in 1912) and Québec's (in the early 1960s) governments. These imposed changes have disrupted the Inuit's traditional way of life, and have contributed to the widening generation gap and the development of the Nunavik's economic and social dependence on the State.

The Westerner history of colonialism and genocide toward the Inuit peoples and cultures is shown by the slaughter of much-needed sled dogs, sedentarization, Inuit family deportations, the creation of residential schools, and the intentional introduction of diseases [38,39]. Indeed, before 1950, most Inuit families lived on the land in close-knit kinship groups of five to thirty people. Each person was valued for their contributions to the wellbeing and success of the group. Inuit traveled around the Inuit territory by dog sled or boat in pursuit of the wildlife that provided most of their food, clothing, and shelter. This deep connection to the land helped the Inuit maintain a rich culture and language. However, after 1950, the Canadian government introduced significant changes in the Baffin region (between 1950 and 1975). Despite being nomads, the Inuit sedentarization was made possible by changes to the fur market, by the impoverishment of the population, and by epidemics and the numerous evacuations of Inuit patients to hospitals far from northern regions. It was a period of considerable environmental transformation in which sled dogs played a central role. The result was an era of traumatic social change, where Inuit moved from a predominantly hunting culture to the logic of great modernism in just over 15 years [40]. Moreover, geographic isolation and the scarcity of microbes in cold climates had not prepared the Inuit immune system for contact with influenza, tuberculosis, or other diseases brought back by the colonizers.

During the period 1871-1969, most non-Aboriginal societies stopped respecting their Aboriginal neighbors. Their interventions in the lives and territories of Aboriginals intensified as the dominant culture adopted policies to forcibly absorb Indigenous lands and peoples while attempting to destroy and denigrate all Indigenous cultures. Canadian colonizers have intentionally attempted to eradicate Indigenous peoples (including the Inuit) through land dispossession, occupation, war, disease, and genocide. These tactics directly damaged the close relationship between Indigenous peoples, like Nunavik's Inuit 
population, and their natural environment. Even the settlers had identified this relationship as the very foundation of Indigenous cosmology and identity [38].

Cosmology refers to a branch of philosophy often subsumed under metaphysics. It combines rational speculation and scientific evidence to understand the universe as a set of phenomena [41]. The cultural disruption generated by colonization aggravates the effects of land dispossession to create almost total psychological, physical, and financial dependence on the State [12]. The cumulative and ongoing effects of this dependency crisis form the context in which Inuit peoples live today. The social suffering, unresolved psychophysical harms of colonization, and cultural dislocation have led to a crisis that has severely curtailed Inuit peoples' opportunities to lead autonomous, healthy, and self-sufficient lives at both the individual and collective levels [12].

Like most Indigenous societies, Inuit adhere to a cosmocentric philosophy where concerns go far beyond the individual $[42,43]$. The sacred circle of life paradigm posits that all beings, both material and immaterial, are equal and interdependent. It also places the notion of respect at the center of the Inuit culture and way of life [44].

Indigenous peoples give equal respect and consideration to both humans and nonhumans, as each is believed to have a sacred character [45]. Historically, Inuit peoples have taken a collectivist approach to their social processes, particularly in how they perceive and consider health [46]. In this holistic view, they refer to the physical, spiritual, emotional, and psychological dimensions of health. The extant literature [47-49] already demonstrates the pronounced and dynamic interrelationship between these four dimensions. Therefore, Western medicine's compartmentalized approach to the prevention and treatment of poor health fails to be culturally-sensitive to the complex healthcare dynamic that is expected and needed by Inuit patients [49].

Due to this failure, it is incumbent upon professionals and managers to be sensitive to these treatment gaps and work to address them to develop more inclusive care policies and practices [8]. In this context, CQ is central to ensuring appropriate, quality care. It is critical, then, to understand how leaders can foster the development of an identity that connects people of different races and ethnicities in a manner that is respectful, equitable. In this context, CQ managerial behaviors [2] are essential to the survival, adaptability, and success of Nunavik healthcare organizations. To work effectively with minorities, multicultural groups, and other relevant organizations, leaders must understand foreign cultural rules, norms, and behavior in a culturally appropriate manner.

\section{Methodology}

The purpose of the present study is to identify and describe CQ profiles while developing a better understanding of the dynamics contributing to CQ development among Nunavik healthcare managers. To meet these objectives, two data collection methods were used: Questionnaires and semi-structured interviews. The triangulated use of these two techniques is a strategy favored by the authors who created the CQ model [50]. This dual method contributes to the reliability and accuracy of CQ measurement relies more on obtaining complete and reliable information, specialized knowledge, and the interpersonal skills of individuals. Data collection was conducted between July 2018 and February 2019. First, the participants completed the ECQ-S measurement scale, which the researchers then analyzed using cluster analysis. In the second step, we explored the narratives of intercultural interactions made by the Nunavik healthcare managers to better understand the dynamics specific to each profile identified in step 1.

\subsection{Selection of Participants}

The participants targeted by this study are expatriate program or service managers who worked for one of Nunavik's healthcare facilities between 2010 and 2019. Interviewing these managers is critical because a part of their mandate stipulates that they should call on and help healthcare professionals to provide services that are respectful of and sensitive to Inuit beliefs, values, and cultural practices. Moreover, these healthcare managers are 
even more integral to our research, as they were mandated to culturally adapt the Ministry of Health and Social Services (MSSS) programs and services to the needs of the local environment [51].

Potential participants were identified via the institutions' organizational charts, telephone lists, people met during the principal investigator's professional activities, and professional referrals from other participants. Respondents were also required to meet several selection criteria: (1) Having been a program and service manager for a Nunavik healthcare facility, (2) having worked there for at least six months, (3) having no current active role at the healthcare facility, and finally (4) having come from Québec, but not from an Indigenous background or a First Nations community. At the end of this process, 53 potential participants were identified. For administrative reasons (e.g., their contact details were either not available or invalid), it was impossible to reach eight of the 53 potential participants. Also, eight potential participants did not respond to the invitation, and five refused to participate. The other managers $(n=31)$ agreed to participate in the study either in whole or in part. All participants completed the Expanded Cultural Intelligence Scale (E-CQS) measurement scale $(n=31)$, while only a portion of the managers $(n=17)$ was interviewed. There are two reasons for the decision to interview a smaller group than the one that filled-in the questionnaires. First, the qualitative analyses' findings reached theoretical saturation after eleven interviews [52]. The analysis of the last five interviews did not provide any new elements that could enrich the theory. The principle of theoretical saturation is based on the fact that each unit of additional information provides a little less new information than the previous one until it no longer provides anything new. For a multi-site and intercultural study, Hagaman and Wutich [53] found that sixteen or fewer interviews are sufficient to identify common themes on sites with relatively homogeneous groups. In the present study, participants were identified to represent a homogeneous group with the same criteria (e.g., been a program and service manager for a Nunavik healthcare facility, worked there for at least six months, no current active role at the healthcare facility, etc.). Secondly, it is essential to discuss the fact that this study was carried out in the unique context of Nunavik. Between its geographical remoteness, the consequent difficulty to access in the field, the political context, and the small number of ex-managers make Nunavik's healthcare system extremely difficult to study. Indeed, in some cases, managers even refused to participate in the interview for fear of being recognized by peers.

Data collection was made possible thanks to the relationship of trust that developed with several local actors. It is critical to note that, for seven years, the study's principal investigator held a management position in one of Nunavik's healthcare organizations. This immersive experience helped familiarize the researcher with the field. Also, he has built up his familiarity with the local people and environment throughout his professional practice. During this process, he gained reliable information and reference points that helped the research develop. This particular research approach has brought new elements to light on the CQ model. It also allowed the researcher to build a network of contacts that enabled him to understand the various dynamics related to healthcare management in the region.

\subsection{Data Analysis}

This study's data processing is based on the two measurement methods (E-CQS questionnaire and the semi-structured interviews). Below, we discuss these two methods of data collection and describe how we used these methods to carry out the present study.

\subsubsection{The CQ Measurement Questionnaire (E-CQS)}

The E-CQS, developed by Van Dyne and colleagues [54], enabled us to measure the managers' CQ. This measurement scale evaluates eleven sub-dimensions of CQ (i.e., three sub-dimensions of the metacognitive dimension, three for the motivational, three for the behavioral, and two for the cognitive). We used this scale because there is strong empirical support for its reliability, stability, and validity [55]. The scale was administered after each 
interview, and results were compiled for each of the scale's dimensions and sub-dimension. We then ran a hierarchical cluster analysis of the compiled results using SPSS 23. This statistical analysis method was chosen because it organizes raw data into homogeneous silos [56]. These silos can, in turn, highlight subsets and sub-concepts that may have been impossible to distinguish otherwise. Then, within each cluster, the data are grouped according to a common characteristic [56-58]. Another benefit of this approach is that there are no precise rules on the sample size required for cluster analysis, so small samples are still compatible. For instance, in several classificatory analysis studies, researchers used small groups of ten or fifteen observations [59]. Ultimately, we used hierarchical cluster analysis to classify the thirty-one managers who completed the questionnaire according to their results on each of the matrix's four dimensions, thus creating fairly homogeneous groups. The average value of the cluster centers provided specific profiles for each cluster.

\subsubsection{Semi-Structured Interviews}

The second research method used here was semi-structured interviews. The semistructured interview guide consisted of eight sections according to different themes related to the experience of managers in Nunavik. The questions were oriented toward themes consistent with the CQ model (e.g., cultural knowledge, available resources, culturallycompetent work environment, staff retention, and institutional memory). The interviews were conducted both in-person and over Skype and lasted an average of $75 \mathrm{~min}$. These two interview methods are considered similar in value in psychology literature, which shows that the analysis of interview data collected by videoconferencing is similar to data collected in a traditional setting [60]. The interviews, regardless of method, were also recorded for transcription and qualitative analysis. The general inductive approach was used to identify themes in the textual data [61]. Specifically, the analysis was carried out in three stages. First, the transcripts enabled us to organize the interview content into Word format, thus making it directly accessible for analysis with Dedoose software v.8.3. Once the data files were organized and adapted according to a standard format, the analysis began with a careful reading of the text. During this analysis, specific themes were identified that helped to capture the participants' main idea or topic (Appendix A, Box A1). The content of the interviews was then classified and systematized into different categories (Appendix A, Box A2). Moreover, the questions in the interview guide identify the subjects' main themes (with subcategories corresponding to basic ideas), specific aspects of more general themes or words, and sentence fragments (verbatim).

Furthermore, axial coding [62] was used to (1) compare the collected information, and then (2) group it into categories and subcategories. The different categories obtained by axial coding include the managers' general characteristics, the CI model's four dimensions, and its fourteen sub-dimensions, including the three sub-dimensions (each) of metacognitive, motivational, and behavioral CI (i.e., nine sub-dimensions in total), with cognitive CI's five sub-dimensions. Then, frequently-occurring ideas were specifically coded (i.e., using selective coding) to highlight the categories. The categories obtained are the paradoxes mentioned above that are present in organizations in a foreign environment. The coding tree that emerged while coding the raw data set consists of five main themes, including: (1) Participant characteristics, (2) dimensions of the CI model, (3) the foreign environment, (4) paradoxes, and finally (5) problems encountered on the job. At the end of the coding process, the different passages of the interviews were grouped under five main themes, 17 sub-themes, and 25 codes (Appendix A).

To ensure the validity of the analysis process, two strategies were used. First, two researchers developed coding trees in parallel and independently from the raw data of the first five interviews [61]. The results of the two analyses were compared to assess their level of overlap. This step made it possible to define the different themes, sub-themes, and codes. Secondly, from the consolidated coding tree, the two researchers independently coded the other interviews to ensure the coherence of the categories [61]. No major issues 
emerged as an outcome of this analysis. Dedoose software v.8.3 was used to perform the analyses.

\section{Results}

The results of this study are presented in two stages. First, we describe the results obtained through the cluster analyses. Next, we present the three CQ profiles: (1) The opportunist, (2) the modern missionary, and (3) the seasoned sage.

\subsection{Results of the Cluster Analysis}

The cluster analyses identified three groups that share similar CQ profile characteristics across the four dimensions of CQ [56]. Then, further analyses allowed us to better understand each group's particularities [56-58]. The results of the analyses are presented below in Table 1.

Table 1. Comparison of groups on the variables used to construct the final cluster.

\begin{tabular}{cccc}
\hline & $\begin{array}{c}\text { Opportunist } \\
\boldsymbol{n = 7}\end{array}$ & $\begin{array}{c}\text { Modern Missionary } \\
\boldsymbol{n = 1 8}\end{array}$ & $\begin{array}{c}\text { Seasoned Sage } \\
\boldsymbol{n}=\mathbf{6}\end{array}$ \\
\hline Motivational & 5.34 & 4.81 & 5.50 \\
Metacognitive & 5.11 & 5.68 & 5.56 \\
Behavioral & 3.98 & 5.43 & 6.09 \\
Cognitive & 4.87 & 4.98 & 3.15 \\
\hline
\end{tabular}

\subsection{Managers' $C Q$ Profiles}

As mentioned above, the data analyses identified and described three profiles of Nunavik healthcare managers: (1) The opportunist, (2) the modern missionary, and (3) the seasoned sage. In the following section, the different profiles are presented in detail and are illustrated with quotations from the interviews.

\subsection{The Opportunist}

The data analyses identified seven managers $(n=7)$ with the opportunist profile. The behaviors associated with this profile result in a lower behavioral CQ (3.98). Managers in this category are not always able to adjust their tone, accent, and pace to their environment, failing to convey their messages effectively. They also do not adequately modulate certain non-verbal behaviors, thus further hindering intercultural communication. The following comments from one manager clearly illustrate this aspect of the opportunistic profile:

I don't think before I act or express myself. I tend to be very familiar with the people around me. When I speak or express myself, I move my arms a lot, I touch other people's arms, etc. I think that it's a real challenge for me to adjust my behavior. I need to be more aware of the [other] culture in front of me and be more careful about seeing how they [people in the other culture] perceive my actions. (Manager \#8)

Since opportunist managers' motivations are specific to their needs, values, and ambitions, their extrinsic motivations (e.g., improved employability and potential promotions) drive them to take - at best-a shallow interest in improving their intercultural contacts. The following two managers' comments clearly illustrate these characteristics:

I had applied to two positions, and Nunavik answered first. That's the main reason I went there. Then, the second was to gain new work experience. (Manager \#6)

It wasn't the culture or the people that made me want to go to Nunavik. I wasn't familiar with either. It was a pure accident, an opportunity for an interesting position. (Manager \#10)

Furthermore, opportunists have a basic understanding of the general elements that make up the foreign cultural environment. They are also cursorily familiar with the culture's value systems, as well as its different political and economic themes. Thus, 
despite their purely selfish motivations, opportunists tend to have procedural knowledge about how to co-exist within the foreign community.

Nevertheless, however, since their motivations are extrinsic, opportunists do not use their intercultural knowledge and interactions to be more effective healthcare providers. Instead, opportunists use these interactions for personal reasons, which can be harmful to patients and surrounding communities.

Moreover, in some cases, opportunistic managers do not modulate their behaviors (enough) to be consistent with the foreign environment. More specifically, they do not always adopt behaviors that would enable patients to live as well as possible. For example, in Nunavik, alcohol problems are pervasive, and in some communities, alcohol sales are illegal. As a result of this unfortunate situation, alcohol is becoming increasingly sought after by local people. Worse still, some managers knowingly take advantage of this public health problem by offering alcohol to Inuit as a "gift" in the hopes of gaining personal advantages (e.g., being taken fishing and given special tours). As explained by Manager \#6 below, opportunistic managers do not care about the harm they cause to the Inuit peoples and cultures, as long as they get what they want:

When a person comes back from the south, they take a 40-ounce bottle of alcohol to give to the Inuk person who will take them fishing and hunting for free. We know and ignore the impact of this. We just think about ourselves and what we'll get out of it. (Manager \#6)

For opportunists, then, the extrinsic motivational dimension of CQ provides the energy necessary to acquire new knowledge and develop the cognitive dimension. This new knowledge feeds into reflections on their actions, thus contributing to developing of the metacognitive dimension. However, since these motivations are extrinsic, the manager's reflections do not focus on the success of the cultural experience. Thus, this situation does not lead opportunists to adapt their behavior to their environment. Instead, it leads to a decrease in intrinsic motivation and a sense of ineffectiveness. Consequently, their reflections about action do not contribute to developing the behavioral dimension of $C Q$, which would allow them to adjust to the environment by adopting a critical attitude toward their selfishness.

In the CQ model, the success of intercultural contact is necessary to encourage the individual to repeat the contact experience, thus developing the motivational dimension. To achieve this, the individual must have a global repertoire of coping skills [31]. Opportunists' reasoning is limited to their own needs. Once their personal goals are achieved, their extrinsic motivations weaken, and they disengage. Therefore, they are unable to adapt adequately to the environment, which means that the model's dynamic is interrupted over time. Significantly, several participants mentioned feeling ineffective in several ways, as demonstrated below by Manager \#10:

The factors that make you not stay are that you feel like you're going in circles, that nothing ever moves forward, that everything always takes too long. [...] If you're someone who is really task-oriented and you always want things to go well and get sorted out, you'll always be unhappy and eventually leave. (Manager \#10)

Opportunism does not lead to success. Specifically, opportunists use deceptive manipulation to promote their personal interests. For example, as demonstrated below, some managers use a "double discourse" (Manager \#7) by pretending to act ethically. This pretense is achieved by claiming to want to develop culturally-sensitive care when, in fact, they are seeking to obtain valuable benefits for themselves, as well as to gain political capital. Consider the example provided below by Manager \#7:

Even if you want and know what is good for providing a service that meets the needs of Inuit [peoples], if the political movement says to move in another direction, this is the direction you have to take if you don't want to lose your position or your place. Even though we know that there will not be good results, we will respect the political movement. There is a double discourse, and politics [i.e., senior management and the Ministry] comes first. (Manager \#7) 
Over time, the local people and other managers and professionals see through this facade and understand the managers' true motivations and moral values. Therefore, although leaders may get good CQ scores, others may consider them as inauthentic leaders who reinforce the organization's double discourse. Managers, then, appear to make rational choices, but always choose the options that involve the lowest cost and greatest benefit for themselves. This finding applies to their economic decisions, as well as to decisions they may make in other areas, such as private and political associations.

\subsection{The Modern Missionary}

The data analyses identified 18 managers with the modern missionary profile $(n=18)$ who are characterized by a lower CQ in the motivational dimension (4.81), which refers to an individual's motivation to adapt to foreign cultural situations. This dimension, then, represents a person's ability to harness attention and energy for effective intercultural interactions. As demonstrated in the example below, intrinsic motivations drive modern missionaries to seek intercultural contact actively:

The motivations that led me to work in Nunavik were curiosity, openness to the world, experience in a remote region where I could develop my autonomy-related skills, and personal development. But, like I said, especially curiosity about getting to know new people and discover their customs. (Manager \#2)

Moreover, modern missionaries attribute very few values to the tangible benefits they might enjoy. For instance, below, one participant presented this element by describing his personal experience:

I remember having discussions with co-workers about money. We always talked about extrinsic rewards, retention bonuses, but I don't think that changes anything. These rewards encourage people to come, but not to stay. I got the retention bonus and left; that's not what made me stay. (Manager \#1)

Another quality of modern missionaries is that their fundamental work objective is to feel useful. They value intercultural interactions because such interactions are considered satisfactory in themselves. In other words, modern missionaries feel a sense of personal wellbeing when helping others. Below, one manager summarizes the importance of this motivation well:

When I was a student, I wanted to work internationally. Intercultural [interaction] fascinates me and challenges me. I wanted to go and help in Africa, but in the end, I saw an ad in the newspaper: Come experience Nunavik. It was a win-win situation. I arrived in Kunjjuaq and fell in love. I've been in the North for ten years now. (Manager \#1)

Modern missionaries are also sensitive to the effectiveness of their interactions with people from other cultures. They believe they have good general and specific knowledge of the foreign culture with which they are interacting.

Moreover, solid metacognitive CQ also characterizes modern missionaries. This quality corresponds to the mental processes that enable these managers to be aware of their own thoughts, reflections, and emotions during intercultural interaction, and to reflect on them afterward. Modern missionaries' intrinsic motivation leads them to self-identify with humanitarians and missionaries, as demonstrated in the following quotation from Manager \#1: "I would like to tell you, I don't know why, but it's deep-seated. I love being in a [foreign] cultural context. It's in my DNA and my personality. I'm a bit of a missionary at heart." Conversely, according to Manager \#11, his intrinsic motivation comes from the connections he makes during his work: "The essence of my work is to connect workers and managers in the health system with organizations or representatives of the Inuit population. I feel it is beneficial" (Manager \#11). Thus, as long as modern missionaries get a favorable response from the environment, the model will continue along with its dynamic. If the environmental response to their efforts is negative, however, they must develop mechanisms to adapt to the environment. If they still fail to get a positive environmental response, the result is often the modern missionary's early departure. 
For modern missionaries, the intrinsic motivational dimension provides the energy necessary to acquire new knowledge and develop their cognitive dimension. This new knowledge feeds into reflections about action and contributes to developing the metacognitive dimension. The reflection, then, makes it possible to act in a way that is more adapted to the environment, thus contributing to developing the behavioral dimension. Successful intercultural contact encourages modern missionaries to repeat the contact experience, thus reinforcing the motivational dimension.

However, the modern missionaries must receive a positive response from the environment to maintain this dynamic. Without this response, their sense of effectiveness will be affected, and they will have difficulty achieving their primary goal (i.e., to feel useful). One manager mentioned that his primary motivation for working in Nunavik was to help a population that had multiple needs, combined with a lack of resources. To his surprise, the situation turned out to be very different from what he had imagined. Through his reflections on this misperception, he realized that he had been influenced by prejudices about the Inuit. Unfortunately, this discovery also led the manager to realize that the opportunities for successful collaboration were so limited that disappointment and disinterest replaced his initial enthusiasm. These discoveries even led him to believe that the situation could not change, which was when he considered leaving his position. The following quotation summarizes his comments:

We're taught to come here to work, to help, to support. I would also tell you that we're also starting from the preconceived notion that we hear from other people: [T] he Inuit don't want to work, they're not reliable, they're not this, they're not that. So we're already starting off with prejudices against them without even really knowing them. So I think that's a major shortcoming. Secondly, there's little interprofessional, intercultural collaboration. Will things change? I wouldn't think so. It's discouraging. We can't help; Inuit peoples must be recognized as equal and not inferior beings. (Manager \#2)

Once the CQ dimensions begin to break down like this, the organizational "fit" then becomes difficult, which tends to reduce motivation further. Ultimately, for Manager \#2, the dynamics of the model eventually all faded, and because he felt ineffective, this modern missionary eventually left his position in Nunavik to work elsewhere.

Another feature of modern missionaries is that they adopt ethnocentric behaviors and believe that, through their intercultural experiences, they have learned to understand the people and culture well enough to anticipate their healthcare needs. For example, when planning and programming healthcare services, modern missionaries do not discount their own culture and values and the influence that these values have on their prejudices about foreign people and cultures.

Still, modern missionaries are not unaware that cultural beliefs can influence health issues. Moreover, while they are willing to adapt to foreign cultural contexts and implement culturally-sensitive care, they are unable to do so because they lack internal (e.g., leadership) and external (e.g., infrastructure) resources. Ultimately, although modern missionaries seek to feel useful, and they value cross-cultural interaction highly, they lack the resources necessary to change the current situation. For example, consider the following quotation from Manager \#9:

Resources are insufficient both in terms of infrastructure and competent staff. There are often disruptions in services due to lack of staff. Staff turnover is so high that often there is no one to send to the villages, or positions may remain vacant for months. (Manager \#9)

Notably, one of the characteristics of ethical leaders is a concern for how their decisions affect others [63]. This quality is demonstrated by the quotation below:

The message and values conveyed by the management are a desire to act as a bridge between the values of Nunavik organizations and provincial guidance. [ ... ] It was very challenging for me, but also for many other people, to realize that the message [about culturally-sensitive care] was there, but that the means to implement it were not. It is clear that the services are not meeting the [Inuit population's] needs. (Manager \#11) 
Modern missionaries eventually notice that by making decisions based on Western cultural values, they are having a negative impact on the Inuit population, who have a different view of healthcare than what is being offered.

\subsection{The Seasoned Sage}

The final profile identified via the data analyses was the seasoned sage, which was identified in six managers $(n=6)$. The seasoned sage is characterized by a lower cognitive CQ than the two previous profiles (3.15). This profile refers to knowledge about foreign cultures' values and the economic and political themes they present. Although this knowledge may be perceived as a disadvantage in the context of the CQ measure, it might instead be an advantage when it comes to adapting to foreign environments. Awareness of cognitive limitations leads these managers to evaluate their knowledge downward and to adapt their thoughts and behaviors to each context. Seasoned sage managers express this in various ways, as demonstrated below:

For me, after 30 years, there are still some aspects of the Inuit peoples that remain a mystery. There are still questions even though I spent thirty years with them. (Manager \#7)

When I came to understand something new, a little veil was lifted, revealing an aspect that was there, but that I hadn't seen it or I hadn't been aware of it. (Manager \#7)

Amazingly, seasoned sage managers can distinguish what they think they know from what they really know. This critical metacognitive dimension corresponds to the mental processes that allow individuals to be aware of their thoughts, reflections, and emotions during intercultural interaction. This reflexivity leads seasoned sage managers to better plan intercultural interactions to ensure their success. Individuals with high behavioral CQ exhibit behaviors that are consistent with their environment. As demonstrated below, their awareness of some aspects of their environment enables them to adapt their behavior accordingly:

It took me ten years to understand some things and then start making connections, understanding, and adjusting in my organization and my interactions. (Manager \#7)

We have to adapt to the population we are going to serve-and not the other way around - because otherwise, we will not meet their needs. (Manager \#14)

Moreover, this awareness also leads them to remain mindful of thoughts that emerge in their field of consciousness. As a result of these interactions, they can adjust their thoughts according to newly gathered information [28]. Successful adaptation to different cultural situations leads them to have a positive cultural experience, which motivates them to learn more. The time factor is favorable to this process, since "over time, we understand that some things are not done" (Manager \#3). The knowledge acquired through long periods of practice leads them to a better understanding of the intricacies of their work environment.

For seasoned sage managers, recognizing the limits of their cognitive knowledge helps them to preserve the model's dynamic. Thus, the motivational dimension provides the energy necessary to acquire new knowledge and to develop the cognitive dimension. This new knowledge feeds into a reflection on action and contributes to developing the metacognitive dimension. This reflection, in turn, makes it possible to adapt their actions to the environment, thus contributing to developing the behavioral dimension. Thus, seasoned sage managers have extensive adaptability skills, which leads them to shift their thinking in a way that diminishes the effects of prejudice. Recognition of one's limits contributes to the development of one's cultural skills, which enable seasoned sages to maintain the model's dynamic. The following quotation presents this characteristic of the seasoned sage:

Nowadays, I tell myself that when I was first working in Nunavik, I was prejudiced. But, then you realize that you're not as open as you thought, and you change. I think this [idea] takes shape, it develops [over time]: [E]liminating prejudices, adapting our 
values to other people's values. I see [now] that in our cultural group, people have a lot of prejudices. Sometimes it's hard to manage. (Manager \#3)

Successful intercultural contact encourages individuals to repeat the contact experience, thus developing the motivational dimension. The cycle repeats itself as long as individuals can positively change the intercultural environment. Through their wisdom, they can instill respect and tolerance for foreign cultures, thus reducing conflict and abuse in intercultural contexts. Although largely unexplored, this cycle of the CQ is ripe for further operationalization and empirical validation [64].

Seasoned sages plan healthcare services that focus on the cross-cultural context. They also question their own culture and values and ask how these values influence their prejudices about foreign people's health needs. As demonstrated below, seasoned sages are aware that cultural beliefs can influence healthcare issues:

We can easily see that they feel misunderstood. Culturally-appropriate services and care are much more likely to have a real impact on Inuit health. We've heard [that this is true], and we've observed it [in dealing] with the huge mental health problems up there; they feel misunderstood. Especially since there was also [a high] staff turnover in social services, they had to tell their stories over and over again. So, at a certain point, [this overly-repetitive re-telling of their stories means that] they don't want to [tell them] anymore, and then it doesn't work out [for the new staff]. I think they [Inuit] felt a bit like they're just a number because of the instability, insensitivity, and high turnover. (Manager \#14)

Ultimately, seasoned sage wisdom is also reflected in their behaviors and decisionmaking, which facilitate the planning and programming of culturally-sensitive healthcare practices. They demonstrate a remarkable ability to share ideas for more effective cross-cultural collaboration. Their wisdom also contributes to the quality of intercultural relations, the effectiveness of working in a culturally-foreign environment, and the overall organizational performance.

Additionally, seasoned sages introduce other professionals to culturally-sensitive approaches and can institutionalize a healthcare program adapted to the Inuit population. More effective cross-cultural performance can be seen in patients' relationships with the healthcare system. For instance, managers who have seasoned sage profiles are also more sensitive to patient concerns. Thus, experienced elders promote cultural sensitivity in healthcare services by using ethical conduct in their management activities. As a result, these seasoned sages are generally recognized and valued by their Inuit patients.

\section{Discussion and Conclusions}

The objectives of this study were to develop CQ profiles and to understand the dynamics of the proposed CQ model. The combination of interviews and measurement with E-CQS helped to clarify the dynamics of CQ in the context of healthcare for marginalized populations. Ultimately, data analysis has allowed us to identify three typical managerial profiles: The opportunist, the modern missionary, and the seasoned sage. For each of the profiles, the interactions between the CQ dimensions were described. By positioning the CQ model in a more global perspective, this study provides a vision of relational and environmental interdependence. The models lead to an understanding of CQ oriented toward organizational and systemic processes that are not limited to individual characteristics [22]. In the past, the individualized positioning of cultural competencies has limited the model's ability to reduce healthcare-based inequalities and injustices committed against marginalized communities [22]. Profile analyses revealed that the majority of Nunavik healthcare managers interviewed do not have the desired profiles in terms of cultural competencies and ethical behaviors.

This study makes four major contributions to the literature on CQ. First, it is one of the few original studies to combine the ECQ-S with a qualitative approach (semi-structured interviewing) that provides new insights into the dynamics of CQ in the context of health- 
care for marginalized groups e.g., [26]. Several authors have also stressed the importance of conducting studies to better understand how CQ develops and how the different dimensions of the model interact with each other e.g., $[25,26]$. Thus, the present article fills this gap through the development of managerial profiles, which enables us to address some of these theoretical limitations e.g., [26]. Second, the present study contributes to strategies for measuring and understanding the development of CQ e.g., [65]. As Blasco and colleagues [25] write, it is crucial to test methodologies to modify and refine the CQ concept. Our findings demonstrate the relevance of a triangulated research methodology that combines interviews with the questionnaire (ECQ-S) to better understand the dynamics of the CQ model e.g., [50]. Thus, taking into consideration the theoretical and empirical maturity of the field of CQ research, this study suggests additional elements that could be integrated into measurement instruments that evaluate the CQ model's dynamics, such as combining interviews with the questionnaire (ECQ-S). Third, this study demonstrates the importance of identifying profiles to facilitate executive training and retention. The profiles also enable the interpretation of the results obtained with the E-CQS measurement instrument. Indeed, modes of reasoning partly explain the dynamics of the model and the challenges of measuring CQ. In this context, it is essential to focus on both the measurement (e.g., E-CQS) and the profiles. Fourth, the results show that a high CQ score is not necessarily associated with appropriate behaviors in the workplace. Moreover, a high CQ level is not sufficient to identify the managers who are most likely to adopt ethical leadership behaviors. For example, seasoned sage managers demonstrate that a lower CQ score actually indicates a greater ability to challenge one's knowledge and to develop the skills needed for ethical intercultural behaviors.

Future research should investigate the profiles' external validity to see if they transcend this context. Moreover, the results of this research call for new empirical work from an international and longitudinal perspective. As the analysis of the seasoned sage demonstrates, individuals' ability to adapt themselves to maintain the model's dynamics seems to improve over time. A longitudinal analysis approach would undoubtedly provide a better understanding of this model's dynamics. It would also be interesting to see whether the theory of psychological contract $[66,67]$ could clarify how the CQ model breaks down to the point where an employee finally leaves the organization. This model, which makes it possible to study social exchange, would undoubtedly be a good tool to help us understand the environmental factor's role in the CQ model. Additionally, an intercultural organizational behavior scale could help assess which employees adopt organizational behaviors favorable for their environment. These elements could identify employees who are predisposed to mitigate the impact of certain factors on the CQ model's dimensions.

Author Contributions: Conceptualization, G.M. and D.T.; methodology, G.M.; validation, D.T.; formal analysis, G.M.; investigation, G.M.; writing-review and editing, G.M. and D.T.; supervision, D.T. All authors have read and agreed to the published version of the manuscript.

Funding: This research received no external funding.

Institutional Review Board Statement: The study was conducted according to the guidelines of the Declaration of Helsinki, and approved by the Ethics Committee of École nationale d'administration publique (protocol code CER-ENAP 2018-11 and date of approval 2018-06-11).

Informed Consent Statement: Informed consent was obtained from all subjects involved in the study.

Data Availability Statement: Not applicable.

Conflicts of Interest: The authors declare no conflict of interest. 


\section{Appendix A}

Box A1 Main themes.

Box A1. $(n=5)$.

(1) Participant characteristics, (2) dimensions of the CQ model, (3) the foreign environment, (4) paradoxes, and finally (5) problems encountered on the job.

Box A2 Sub-themes.

Box A2. $(n=17)$.

Intrinsic motivation; extrinsic motivation; sense of self-efficacy; culturally generalizable knowledge; inuit-specific knowledge; planning; awareness; verification; verbal behaviors; non-verbal behaviors; language acts; unique environment; paradoxes; inuit training; expatriate manager training; work environment; time management.

Box A3 Codes.

Box A3. $(n=25)$.

Motivations to go; motivations to stay; motivations to leave; sense of effectiveness; previous experience; specific interests in intercultural management; knowledge of legal, economic, and political systems; knowledge of various values and norms; interests; training; experiences; barriers; strategies; judgment; impact of differences; challenging and adjusting; historical context; political context; values; organizational fit; staff turnover/retention rate; absenteeism from work; compliance with policies and procedures; institutional memory; communication; skills; training.

\section{References}

1. Earley, P.C.; Peterson, R.S. The elusive cultural chameleon: Cultural intelligence as a new approach to intercultural training for the global manager. Acad. Manag. Learn. Educ. 2004, 3, 100-115. [CrossRef]

2. Lozano, J.F.; Escrich, T. Cultural diversity in business: A critical reflection on the ideology of tolerance. J. Bus. Ethics 2017, 142, 679-696. [CrossRef]

3. Smith, P.B.; Peterson, M.F.; Thomas, D.C. The Handbook of Cross-Cultural Management Research; Sage Publications: Thousand Oaks, CA, USA, 2008.

4. Thomas, D.C.; Elron, E.; Stahl, G.; Ekelund, B.Z.; Ravlin, E.C.; Cerdin, J.L.; Maznevski, M. Cultural intelligence: Domain and assessment. Int. J. Cross Cult. Manag. 2008, 8, 123-143. [CrossRef]

5. Lefebvre, D. Les Emplois au Nunavik, Service de L'emploi Durable, ARK Rapport D'enquête. 2011. Available online: http:/ / www.krg.ca/images/stories/docs/Employment_and_Training/French/Les\%20Emplois\%20au\%20Nunavik\%202011 \%20fr.pdf (accessed on 20 August 2018).

6. Paquin, V.; Sandy, G.; Perrault-Sullivan, G.; Fortin, G.; Cauchon, M.; Fletcher, C.; Ouellet, J.; Lemire, M. Twenty "must-read" research articles for primary care providers in Nunavik: Scoping study and development of an information tool. Int. J. Circumpolar Health 2019, 78, 1578638. [CrossRef] [PubMed]

7. Hordyk, S.R.; Macdonald, M.E.; Brassard, P. End-of-life care in Nunavik, Quebec: Inuit experiences, current realities, and ways forward. J. Palliat. Med. 2017, 20, 647-655. [CrossRef]

8. Mbuzi, V.; Fulbrook, P.; Jessup, M. Indigenous peoples' experiences and perceptions of hospitalisation for acute care: A metasynthesis of qualitative studies. Int. J. Nurs. Stud 2017, 71, 39-49. [CrossRef]

9. Van Wagner, V.; Osepchook, C.; Harney, E.; Crosbie, C.; Tulugak, M. Remote midwifery in Nunavik, Quebec, Canada: Outcomes of perinatal care for the Inuulitsivik health centre, 2000-2007. Birth 2012, 39, 230-237. [CrossRef] [PubMed]

10. Inuit Tapiriit Kanatami (ITK). Social Determinants of Inuit Health in Canada, Ottawa. 2014. Available online: https:/ /www.itk. ca/wp-content/uploads/2016/07/ITK_Social_Determinants_Report.pdf (accessed on 20 August 2018).

11. Zghal, A.; El-Masri, M.; McMurphy, S.; Pfaff, K. Exploring the Impact of Healthcare Provider Cultural Competence on New Immigrant Health-Related Quality of Life: A Cross-Sectional Study of Canadian Newcomers. J. Transcult. Nurs. 2020. [CrossRef] [PubMed]

12. Alfred, T.; Corntassel, J. Colonialism and State Dependency. J. Aborig. Health 2009, 5, 42-60.

13. Brave Heart, M. Conversations about Historical Trauma: Part One. In IMPACT Newsletter; Child Traumatic Stress Network, Spring: Los Angeles, CA, USA, 2013. 
14. Brave Heart, M. The historical trauma response among natives and its relationship with substance abuse: A Lakota illustration. J. Psychoact. Drugs 2003, 35, 7-13. [CrossRef] [PubMed]

15. Brave Heart, M.; Debruyn, L.M. The American Indian Holocaust: Healing historical unresolved grief. American Indian and Alaska native mental health research. J. Natl. Center 1998, 8, 56-78.

16. Crawford, A. Inuit take action towards suicide prevention. Lancet 2016, 388, 1036-1038. [CrossRef]

17. Lestage, C.; Dubuc, N.; Bravo, G. Développement et validation d'une classification québécoise des résidences privées avec services accueillant des personnes âgées. Can. J. Aging Rev. Can. Vieil. 2014, 33, 72-83. [CrossRef] [PubMed]

18. Downing, R.; Kowal, E.; Paradies, Y. Indigenous cultural training for health workers in Australia. Int. J. Qual. Healthc. 2011, 23, 247-257. [CrossRef] [PubMed]

19. McEldowney, R.; Connor, M.J. Cultural safety as an ethic of care: A praxiological process. J. Transcult. Nurs. 2011, 22, 342-349. [CrossRef] [PubMed]

20. Truong, M.; Paradies, Y.; Priest, N. Interventions to improve cultural competency in healthcare: A systematic review of reviews. BMC Health Serv. Res. 2014, 14, 1-17. [CrossRef]

21. Beach, M.C.; Price, E.G.; Gary, T.L.; Robinson, K.A.; Gozu, A.; Palacio, A.; Smarth, C.; Jenckes, M.W.; Feuerstein, C.; Bass, E.B.; et al. Cultural competency: A systematic review of healthcare provider educational interventions. Med. Care 2005, 43, 356. [CrossRef]

22. Curtis, E.; Jones, R.; Tipene-Leach, D.; Walker, C.; Loring, B.; Paine, S.J.; Reid, P. Why cultural safety rather than cultural competency is required to achieve health equity: A literature review and recommended definition. Int. J. Equity Health 2019, 18, 1-17. [CrossRef] [PubMed]

23. Redvers, N.; Schultz, C.; Vera Prince, M.; Cunningham, M.; Jones, R.; Blondin, B.S. Indigenous perspectives on education for sustainable healthcare. Med. Teach. 2020, 42, 1085-1090. [CrossRef]

24. Earley, P.C.; Ang, S. Cultural Intelligence: Individual Interactions Across Cultures; Stanford University Press: Palo Alto, CA, USA, 2003.

25. Blasco, M.; Feldt, L.E.; Jakobsen, M. If only cultural chameleons could fly too: A critical discussion of the concept of cultural intelligence. Int. J. Cross Cult. Manag. 2012, 12, 229-245. [CrossRef]

26. Ott, D.L.; Michailova, S. Cultural intelligence: A review and new research avenues. Int. J. Manag. Rev. 2018, 20, 99-119. [CrossRef]

27. Sousa, C.; Gonçalves, G. Expatriates and non-expatriates: Effects of cultural intelligence and multicultural personality on passion for work and satisfaction with life. Psychol. Thought 2017, 10, 90-108. [CrossRef]

28. Ang, S.; Van Dyne, L. Handbook of Cultural Intelligence; Routledge: London, UK, 2015.

29. Livermore, D. The Cultural Intelligence Difference: Master the One Skill You Can't Do without in Today's Global Economy; AMACOM Div American Mgmt Assn: New York, NY, USA, 2011.

30. Livermore, D. Leading with Cultural Intelligence: The New Secret to Success; AMACOM Div American Mgmt Assn: New York, NY, USA, 2009.

31. Livermore, D.; Van Dyne, L.; Ang, S. Cultural intelligence: Why every leader needs it. Int. Manag. Q. 2012, 13, 18-21.

32. Régie Régionale de la Santé et des Services Sociaux Nunavik (RRSSSN) en collaboration avec l'Institut national de santé publique du Québec. Faits saillants. Portrait de Santé du Nunavik 2015-Les Enfants et Leur Famille, les Jeunes, les Adultes et les Ainés; Gouvernement du Québec: Québec, QC, Canada, 2015; 18p.

33. Régie Régionale de la Santé et des Services Sociaux Nunavik (RRSSSN) en collaboration avec l'Institut national de santé publique du Québec. Portrait de Santé du Nunavik 2014—Les Jeunes Enfants et Leur Famille; Gouvernement du Québec: Québec, QC, Canada, 2015; 90p.

34. Pollock, N.J.; Healey, G.K.; Jong, M.; Valcour, J.E.; Mulay, S. Tracking progress in suicide prevention in Indigenous communities: A challenge for public health surveillance in Canada. BMC Public Health 2018, 18, 1320. [CrossRef]

35. Truth and Reconciliation Commission of Canada (TRC). Honouring the Truth, RECONCILING for the future: Summary of the Final Report of the Truth and Reconciliation Commission of Canada; Truth and Reconciliation Commission of Canada: Winnipeg, MB, Canada, 2015.

36. Lavoie, F.; Muckle, G.; Fraser, S.; Boucher, O. Epidemiological portrait of physical violence and property offences in Nunavik. In Nunavik Inuit Health Survey 2004: Qanuippitaa? How are we? St-Laurent, D., Dewailly, É, Déry, S., Eds.; Institut national de santé publique du Québec, Régie régionale de la santé et des services sociaux du Nunavik: Québec, QC, Canada, 2007; 13p.

37. Ladner, K.; Orsini, M. The Persistence of Paradigm Paralysis: The First Nations Governance Act as the Continuation of Colonial Policy; In Canada: The State of Federation 2003 Reconfiguring Aboriginal-State Relations; Murphy, M., Ed.; Institute of Intergovernmental Relations: Kingston, ON, Canada; McGill-Queen's University Press: Montreal, QC, Canada, 2005 ; pp. 185-206.

38. Alfred, T. En finir avec le bon sauvage. Nouv. Cah. Soc. 2017, 18, 65-70.

39. Tester, F. Mad dogs and (mostly) Englishmen: Colonial relations, commodities, and the fate of Inuit sled dogs. Études/Inuit/Stud. 2010, 34, 129-147. [CrossRef]

40. Tester, F.; Kulchyski, P. Tammarniit (mistakes): Inuit relocation in the eastern Arctic, 1939-63; UBC Press: Vancouver, BC, Canada, 1994.

41. Weick, K.E. The collapse of sensemaking in organizations: The Mann Gulch disaster. Adm. Sci. Q. 1993, 628-652. [CrossRef]

42. Karmis, D. Cultures autochtones et libéralisme au Canada: Les vertus médiatrices du communautarisme libéral de Charles Taylor. Can. J. Political Sci. Rev. Can. Sci Polit. 1993, 26, 69-96. [CrossRef] 
43. Laugrand, F. Pour en finir avec la spiritualité: l'esprit du corps dans les cosmologies autochtones du Québec. In Les Autochtones et le Québec: Rencontres Historiques, Politiques, Sociales et Culturelles; Beaulieu, A., Gervais, S., Papillon, S., Eds.; Presses de l’Université de Montréal: Montreal, QC, Canada, 2013; pp. 113-132.

44. Sioui, G.E. Pour une Autohistoire Amérindienne. In Essai sur les Fondements d'une Morale Sociale; Trigger, B.G., Ed.; Les Presses de l'Université Laval: Québec, QC, Canada, 1989; 157p.

45. Beauclair, N. Épistémologies autochtones et décolonialité: Réflexions autour de la philosophie interculturelle latino-américaine. Rech. Amérindiennes Québec 2015, 45, 67-76. [CrossRef]

46. Arnaert, A.; Schaack, G. Cultural awareness of Inuit patients' experiences with emergency nursing care. Accid. Emerg. Nurs. 2006, 14, 97-103. [CrossRef] [PubMed]

47. Bear, L.L. Jagged worldviews colliding. In Reclaiming Indigenous Voice and Vision; Barman Jab, M., Ed.; First Nations Education in Canada: The Circle Unfolds; UBC Press: Vancouver, BC, Canada, 2000; pp. 77-85.

48. Durie, M. Understanding health and illness: Research at the interface between science and indigenous knowledge. Int. J. Epidemiol. 2004, 33, 1138-1143. [CrossRef]

49. Richmond, C.A.; Ross, N.A.; Bernier, J. Exploring Indigenous Concepts of Health: The Dimensions of Métis and Inuit Health. In Aboriginal Policy Research: Directions and Outcomes; White, J., Beavon, D., Wingert, S., Maxim, P., Eds.; Thompson Educational Publishing: Toronto, ON, Canada, 2007; Volume 4, pp. 3-13.

50. Earley, P.C.; Ang, S.; Tan, J.S. CQ: Developing Cultural Intelligence at Work; Stanford University Press: Palo Alto, CA, USA, 2006.

51. Régie Régionale de la Santé et des Services Sociaux Nunavik (RRSSSN). Plan D'organisation; Gouvernement du Québec: Québec, QC, Canada, 2018; 34p.

52. Saunders, B.; Sim, J.; Kingstone, T.; Baker, S.; Waterfield, J.; Bartlam, B.; Burroughs, H.; Jinks, C. Saturation in qualitative research: Exploring its conceptualization and operationalization. Qual. Quant. 2018, 52, 1893-1907. [CrossRef]

53. Hagaman, A.K.; Wutich, A. How many interviews are enough to identify metathemes in multisited and cross-cultural research? Another perspective on Guest, Bunce, and Johnson's (2006) landmark study. Field Methods 2017, 29, 23-41. [CrossRef]

54. Van Dyne, L.; Ang, S.; Ng, K.Y.; Rockstuhl, T.; Tan, M.L.; Koh, C. Sub-dimensions of the four factor model of cultural intelligence: Expanding the conceptualization and measurement of cultural intelligence. Soc. Personal. Psychol. Compass 2012, 6, 295-313. [CrossRef]

55. Ng, K.Y.; Van Dyne, L.; Ang, S.; Ryan, A.M. Cultural intelligence: A review, reflections, and recommendations for future research. Conducting multinational research. Appl. Organ. Psychol. Workplace 2012, 29-58. [CrossRef]

56. Hair, J.F.; Black, W.C.; Babin, B.J.; Anderson, R.E.; Tatham, R.L. Multivariate Data Analysis; Pearson Prentice Hall: Upper Saddle River, NJ, USA, 2006; Volume 6.

57. Everitt, B.S.; Landau, S.; Leese, M. Cluster Analysis, 4th ed.; A Member of the Hodder Headline Group, London: Arnold; Wiley Publishing: Hoboken, NJ, USA, 2001; pp. 429-438.

58. Igloliorte, H.L.; Legacy of Hope Foundation. We Were So Far Away: The Inuit Experience of Residential Schools; Legacy of Hope Foundation: Ottawa, ON, Canada, 2010.

59. Dolnicar, S. A Review of Unquestioned Standards in Using Cluster Analysis for Data-Driven Market Segmentation. 2002. Available online: https:/ / ro.uow.edu.au/commpapers/273 (accessed on 28 February 2021).

60. Haddouk, L. Télépsychologie et visioconsultation. In Annales Médico-Psychologiques, Revue Psychiatrique; Elsevier Masson: Paris, France, 2018; Volume 176, pp. 278-281.

61. Thomas, D.R. A general inductive approach for analyzing qualitative evaluation data. Am. J. Eval. 2006, 27, 237-246. [CrossRef]

62. Strauss, A.; Corbin, J.M. Grounded Theory in Practice, 2nd ed.; Sage: Newbury Park, CA, USA, 1998.

63. Murphy, P.E.; Enderle, G. Managerial ethical leadership: Examples do matter. Bus. Ethics Q. 1995, 5, 117-128. [CrossRef]

64. Sharma, N.; Hussain, D. Current status and future directions for cultural intelligence. J. Intercult. Commun. Res. 2017, 46, 96-110. [CrossRef]

65. Bücker, J.; Furrer, O.; Lin, Y. Measuring cultural intelligence (CQ) A new test of the CQ scale. Int. J. Cross Cult. Manag. 2015, 15, 259-284. [CrossRef]

66. Guerrero, S. La mesure du contrat psychologique dans un contexte de travail francophone. Relat. Ind. Ind. Relat. 2005, 60, 112-144.

67. Rousseau, D.M. New hire perceptions of their own and their employer's obligations: A study of psychological contracts. J. Organ. Behav. 1990, 11, 389-400. [CrossRef] 